\title{
Circulating Monocyte Chemoattractant Protein-1 Levels and Lumbar Bone Mineral Density in Korean Women
}

\author{
Seong-Kyu Lee* \\ Department of Biochemistry-Molecular Biology, Eulji University School of Medicine, Daejeon; Department of Internal Medicine, Eulji University Hospital, Daejeon, \\ Korea
}

Background: Monocyte chemoattractant protein-1 (MCP-1) is expressed in adipose tissue, macrophages, endothelial cells, and osteoblasts by parathyroid hormone administration. Circulating MCP-1 levels are positively correlated with the degree of obesity. However, whether circulating MCP-1 affects bone metabolism is unclear. Therefore, in this study, the association between circulating MCP-1 levels and lumbar bone mineral density (BMD) based on menopausal status was assessed.

Methods: We recruited 109 premenopausal and 46 postmenopausal Korean women and examined the association between circulating MCP-1 concentrations and various parameters including lumbar BMD based on menopausal status.

Results: A significant increase in body weight, abdominal circumference, body mass index, and MCP-1 levels (from $245.9 \pm 73.5$ to $336.5 \pm 101.7 \mathrm{pg} / \mathrm{mL}$ ) and significant decrease (from $0.992 \pm 0.114$ to $0.772 \pm 0.113 \mathrm{~g} / \mathrm{cm}^{2}$ ) in lumbar BMD were observed after menopause. However, circulating MCP-1 levels were not correlated with any parameters including lumbar BMD in premenopausal or postmenopausal women.

Conclusion: Circulating MCP-1 levels were not correlated with lumbar BMD regardless of menopausal status.

Key words: Monocyte chemoattractant protein-1, Bone density, Women

\author{
Received November 11, 2017 \\ Reviewed November 20, 2017 \\ Accepted November 29, 2017 \\ *Corresponding author \\ Seong-Kyu Lee \\ (10) \\ https://orcid.org/0000-0002-5999-7656 \\ Department of Biochemistry-Molecular \\ Biology, Eulji University School of \\ Medicine, 77 Gyeryong-ro 771 beon-gil, \\ Jung-gu, Daejeon 34824, Korea \\ Tel: +82-42-259-1642 \\ Fax: +82-42-259-1539 \\ E-mail: Iskendo@hanmail.net
}

\section{INTRODUCTION}

Chemotactic cytokine, monocyte chemoattractant protein-1 (MCP-1)/C-C motif chemokine ligand 2 is a major ligand for $\mathrm{C}-$ $\mathrm{C}$ motif chemokine receptor $2 \cdot{ }^{1-3} \mathrm{MCP}-1$ and its receptor, $\mathrm{C}-\mathrm{C}$ motif chemokine receptor 2 , are important for monocyte and macrophage recruitment in inflammation. $.^{3-5} \mathrm{MCP}-1$ is overexpressed in the adipose tissue of obese rodents. ${ }^{4,6,7}$ In various ethnic populations ${ }^{8-13}, \mathrm{MCP}-1$ expression is higher in obese individuals and in visceral adipose tissue and positively associated with obesity or insulin resistance. MCP-1 is expressed in various types of cells such as vascular endothelium, fibroblasts, smooth muscle cells, and mo- nocytic cells. ${ }^{14}$ In addition, osteoblast lineage cells in the bone marrow were shown to express increased MCP-1 after parathyroid hormone (PTH) administration. ${ }^{14}$ Tamasi et al. ${ }^{14}$ showed that MCP-1 in bone is a core mediator for the anabolic effect of human PTH (1-34). Therefore, it is speculated that circulating MCP-1 levels (not MCP-1 secreted by bone cells) are possibly associated with bone metabolism. Sukumar et al. ${ }^{15}$ demonstrated serum MCP-1 levels were positively associated with bone turnover markers in lean women but not obese women, and were weakly associated with femoral neck and hip bone mineral density (BMD) in both types of women $(P<0.09)$. However, the authors did not analyze the study results based on menopausal status or use lumbar BMD. 
In our previous study ${ }^{16}$, circulating MCP-1 concentrations were associated with menopausal status, irrespective of obesity. Therefore, in the present study, we assessed the association between circulating MCP-1 levels and lumbar BMD based on menopausal status in Korean women.

\section{METHODS}

The subjects in the present study were recruited during our previous study ${ }^{16}$ at the Eulji University Hospital in Korea from January 2003 to October 2004. Informed consent was obtained from the study participants. This study was approved by the Institutional Review Board of Eulji University in Daejeon, Korea (IRB No. EU 07-10). We evaluated 109 premenopausal women and 46 postmenopausal women who had no endocrinologic, hepatic, renal, pulmonary, or cardiovascular disease, with the allowed exceptions of hypertension, dyslipidemia, impaired fasting glucose, and obesity (body mass index $[\mathrm{BMI}], \geq 25 \mathrm{~kg} / \mathrm{m}^{2}$ ). Study participants did not take any medications that affected blood glucose and lipid levels, metabolism, or obesity. Based on menstrual history, postmenopausal women were postmenopausal for more than 1 year. They reached menopause naturally and were not taking estrogen or pro-

Table 1. The clinical profiles of premenopausal and postmenopausal women

\begin{tabular}{lccr}
\hline Parameter & $\begin{array}{c}\text { Premenopausal } \\
\text { women (n=109) }\end{array}$ & $\begin{array}{c}\text { Postmenopausal } \\
\text { women }(\mathrm{n}=46)\end{array}$ & $P$ \\
\hline Age (yr) & $39 \pm 6$ & $60 \pm 6^{\dagger}$ & $<0.001$ \\
Body weight (kg) & $55.5 \pm 7.0$ & $58.9 \pm 9.5^{*}$ & 0.015 \\
Abdominal circumference (cm) & $73 \pm 7$ & $84 \pm 8^{\dagger}$ & $<0.001$ \\
BMI (kg/m²) & $22.2 \pm 2.7$ & $25.3 \pm 3.7^{\dagger}$ & $<0.001$ \\
Systolic BP (mmHg) & $116 \pm 13$ & $141 \pm 22^{\dagger}$ & $<0.001$ \\
Diastolic BP (mmHg) & $69 \pm 9$ & $79 \pm 13^{\dagger}$ & $<0.001$ \\
Total cholesterol (mg/dL) & $182 \pm 31$ & $215 \pm 42^{\dagger}$ & $<0.001$ \\
Triglyceride (mg/dL) & $95 \pm 68$ & $119 \pm 48^{*}$ & 0.031 \\
HDL cholesterol (mg/dL) & $54 \pm 10$ & $53 \pm 12$ & 0.634 \\
LDL cholesterol (mg/dL) & $109 \pm 28$ & $137 \pm 40^{\dagger}$ & $<0.001$ \\
Fasting glucose (mg/dL) & $83 \pm 8$ & $90 \pm 11^{\dagger}$ & 0.001 \\
Lumbar BMD (g/cm²) & $0.992 \pm 0.114$ & $0.772 \pm 0.113^{\dagger}$ & $<0.001$ \\
MCP-1 (pg/mL) & $245.9 \pm 73.5$ & $336.5 \pm 101.7^{\dagger}$ & $<0.001$ \\
\hline
\end{tabular}

Values are presented as mean \pm standard deviation. Student $t$-test was performed between the premenopausal and postmenopausal groups.

${ }^{*} P<0.05 ;{ }^{\dagger} P<0.01$, between premenopausal and postmenopausal groups.

$\mathrm{BMI}$, body mass index; BP, blood pressure; HDL, high-density lipoprotein; LDL, low-density lipoprotein; BMD, bone mineral density; MCP-1, monocyte chemoattractant protein-1. gestin and estrogen pills. We performed several anthropometric measurements including body weight, abdominal circumference, and BMI; we also measured serum MCP-1 levels, various blood parameters, and lumbar spine L1-L4 BMD using dual energy Xray absorptiometry (Norland Corp., Fort Atkinson, WI, USA). Data were represented as mean \pm standard deviation. A $P<0.05$ was considered statistically significant. All statistical analyses were performed using SPSS version 12.0 (SPSS Inc., Chicago, IL, USA). Student $t$-tests were performed to compare the various parameters between premenopausal and postmenopausal women. Pearson correlation analyses for parametric distribution were performed to examine the association between circulating MCP-1 levels and various laboratory and clinical parameters including BMD, in premenopausal and postmenopausal women.

\section{RESULTS}

The mean age of premenopausal women was 39 years and of postmenopausal women 60 years. A significant increase in body weight ( $55.5 \pm 7.0$ vs. $58.9 \pm 9.5 \mathrm{~kg})$, abdominal circumference

Table 2. Pearson correlation analyses of circulating MCP-1 levels with lumbar $\mathrm{BMD}$ and other parameters in premenopausal and postmenopausal women

\begin{tabular}{|c|c|c|c|c|}
\hline \multirow{3}{*}{ Variable } & \multicolumn{2}{|c|}{$\begin{array}{l}\text { Premenopausal } \\
\text { women }(n=109)\end{array}$} & \multicolumn{2}{|c|}{$\begin{array}{c}\text { Postmenopausal } \\
\text { women }(n=46)\end{array}$} \\
\hline & \multicolumn{4}{|c|}{ Circulating MCP-1 levels (pg/mL) } \\
\hline & $r$ & $P$ & $r$ & $P$ \\
\hline Age (yr) & 0.156 & 0.106 & -0.024 & 0.876 \\
\hline Body weight (kg) & 0.158 & 0.100 & -0.100 & 0.511 \\
\hline Abdominal circumference (cm) & 0.131 & 0.177 & 0.009 & 0.957 \\
\hline $\mathrm{BMI}\left(\mathrm{kg} / \mathrm{m}^{2}\right)$ & 0.154 & 0.110 & -0.075 & 0.626 \\
\hline Systolic BP (mmHg) & 0.014 & 0.882 & 0.018 & 0.908 \\
\hline Diastolic BP (mmHg) & -0.029 & 0.764 & 0.043 & 0.781 \\
\hline Total cholesterol (mg/dL) & 0.111 & 0.251 & 0.159 & 0.302 \\
\hline Triglyceride (mg/dL) & 0.050 & 0.607 & 0.118 & 0.439 \\
\hline HDL cholesterol (mg/dL) & 0.084 & 0.389 & -0.079 & 0.606 \\
\hline LDL cholesterol (mg/dL) & 0.071 & 0.467 & 0.165 & 0.284 \\
\hline Fasting glucose (mg/dL) & -0.034 & 0.725 & 0.088 & 0.564 \\
\hline Lumbar BMD (g/cm²) & 0.070 & 0.470 & -0.121 & 0.436 \\
\hline
\end{tabular}

Pearson correlation analyses were performed to examine the association between circulating MCP-1 concentrations and lumbar BMD or other parameters in premenopausal and postmenopausal women, respectively.

MCP-1, monocyte chemoattractant protein-1; BMD, bone mineral density; BMl, body mass index; BP, blood pressure; HDL, high-density lipoprotein; LDL, low-density lipoprotein. 
( $73 \pm 7$ vs. $84 \pm 8 \mathrm{~cm})$, BMI $\left(22.2 \pm 2.7\right.$ vs. $\left.25.3 \pm 3.7 \mathrm{~kg} / \mathrm{m}^{2}\right)$, systolic blood pressure ( $116 \pm 13$ vs. $141 \pm 22 \mathrm{mmHg})$, diastolic blood pressure ( $69 \pm 9$ vs. $79 \pm 13 \mathrm{mmHg})$, serum total cholesterol (182 \pm 31 vs. $215 \pm 42 \mathrm{mg} / \mathrm{dL}$ ), triglycerides (95 \pm 68 vs. $119 \pm 48 \mathrm{mg} / \mathrm{dL}$ ), low-density lipoprotein cholesterol (109 \pm 28 vs. $137 \pm 40 \mathrm{mg} / \mathrm{dL})$, fasting glucose ( $83 \pm 8$ vs. $90 \pm 11 \mathrm{mg} / \mathrm{dL})$, and MCP-1 (245.9 \pm 73.5 vs. $336.5 \pm 101.7 \mathrm{pg} / \mathrm{mL}$ ) levels, and significant decrease in lumbar BMD (0.992 \pm 0.114 vs. $\left.0.772 \pm 0.113 \mathrm{~g} / \mathrm{cm}^{2}\right)$ were observed after menopause, as shown in Table 1. However, circulating MCP-1 levels were not correlated with any anthropometric data, blood parameters, or lumbar BMD in premenopausal or postmenopausal women, as shown in Table 2.

\section{DISCUSSION}

Tamasi et al. ${ }^{14}$ demonstrated MCP-1 was secreted by the osteoblast lineage cells in response to PTH administration and was necessary for the recruitment of preosteoclastic cells and the formation of mature osteoclasts. The transient increase in osteoclastic activity causes a subsequent increase in bone formation, responsible for a net increase of bone mass due to PTH administration. ${ }^{14}$ Therefore, MCP-1 is considered to mediate the anabolic effect of PTH on bone. ${ }^{14}$ However, whether circulating MCP-1 (not MCP-1 secreted by bone cells) affects bone metabolism is unclear. Sukumar et al. ${ }^{15}$ demonstrated serum MCP-1 levels were positively associated with osteocalcin and propeptide of type 1 collagen in lean women but not obese women, and were not significantly correlated with femoral neck and hip BMD regardless of BMI status. The subjects in Sukumar et al.s study ${ }^{15}$ were women between 25 and 71 years of age and were not divided based on menopausal status during the analysis. In our previous study ${ }^{16}$, circulating MCP-1 levels were not significantly different between non-obese and obese women in premenopausal and postmenopausal women, respectively, despite different degrees of obesity in terms of BMI and abdominal circumference. Specifically, circulating MCP-1 levels were associated with menopausal status irrespective of obesity. ${ }^{16}$ Therefore, in the present study, we assessed the association between circulating MCP-1 levels and lumbar BMD (not femoral neck and hip BMD) based on menopausal status. In our study, circulating MCP-1 levels increased and lumbar BMD decreased after menopause. However, circulating MCP-1 levels were not correlated with any anthropometric data, blood parameters, or lumbar BMD regardless of menopausal status. Prospective studies in various populations involving many subjects with obesity or lean body mass are required to determine the association between circulating MCP-1 levels and lumbar and femoral BMD. This study had several limitations. First, we did not analyze the correlation between serum MCP-1 levels and BMD after adjusting for serum 25-OH-vitamin $\mathrm{D}_{3}$ and intact PTH levels. Second, we used only lumbar BMD without femoral BMD in the analysis. Third, the number of subjects in this study was small.

\section{CONFLICTS OF INTEREST}

The author declares no conflict of interest.

\section{ACKNOWLEDGMENTS}

This research was supported by EMBRI Grants 2016 from the Eulji University, Daejeon, Korea (No. 2016-EMBRIDJ0001).

\section{REFERENCES}

1. Robinson EA, Yoshimura T, Leonard EJ, Tanaka S, Griffin PR, Shabanowitz J, et al. Complete amino acid sequence of a human monocyte chemoattractant, a putative mediator of cellular immune reactions. Proc Natl Acad Sci U S A 1989;86: 1850-4.

2. Kurihara T, Bravo R. Cloning and functional expression of mCCR2, a murine receptor for the $\mathrm{C}-\mathrm{C}$ chemokines JE and FIC. J Biol Chem 1996;271:11603-7.

3. Charo IF, Taubman MB. Chemokines in the pathogenesis of vascular disease. Circ Res 2004;95:858-66.

4. Kamei N, Tobe K, Suzuki R, Ohsugi M, Watanabe T, Kubota $\mathrm{N}$, et al. Overexpression of monocyte chemoattractant protein-1 in adipose tissues causes macrophage recruitment and insulin resistance. J Biol Chem 2006;281:26602-14.

5. Weisberg SP, Hunter D, Huber R, Lemieux J, Slaymaker S, Vaddi K, et al. CCR2 modulates inflammatory and metabolic effects of high-fat feeding. J Clin Invest 2006;116:115-24.

6. Sartipy P, Loskutoff DJ. Monocyte chemoattractant protein 1 
in obesity and insulin resistance. Proc Natl Acad Sci U S A 2003; 100:7265-70.

7. Sell H, Eckel J. Monocyte chemotactic protein-1 and its role in insulin resistance. Curr Opin Lipidol 2007;18:258-62.

8. Christiansen T, Richelsen B, Bruun JM. Monocyte chemoattractant protein-1 is produced in isolated adipocytes, associated with adiposity and reduced after weight loss in morbid obese subjects. Int J Obes (Lond) 2005;29:146-50.

9. Kim CS, Park HS, Kawada T, Kim JH, Lim D, Hubbard NE, et al. Circulating levels of MCP-1 and IL-8 are elevated in human obese subjects and associated with obesity-related parameters. Int J Obes (Lond) 2006;30:1347-55.

10. Malavazos AE, Cereda E, Morricone L, Coman C, Corsi MM, Ambrosi B. Monocyte chemoattractant protein 1: a possible link between visceral adipose tissue-associated inflammation and subclinical echocardiographic abnormalities in uncomplicated obesity. Eur J Endocrinol 2005;153:871-7.

11. Herder C, Baumert J, Thorand B, Koenig W, de Jager W, Meisinger $\mathrm{C}$, et al. Chemokines as risk factors for type 2 diabetes: results from the MONICA/KORA Augsburg Study, 1984-2002. Diabetologia 2006;49:921-9.

12. Mine S, Okada Y, Tanikawa T, Kawahara C, Tabata T, Tanaka
Y. Increased expression levels of monocyte CCR2 and monocyte chemoattractant protein-1 in patients with diabetes mellitus. Biochem Biophys Res Commun 2006;344:780-5.

13. Piemonti L, Calori G, Mercalli A, Lattuada G, Monti P, Garancini MP, et al. Fasting plasma leptin, tumor necrosis factoralpha receptor 2 , and monocyte chemoattracting protein 1 concentration in a population of glucose-tolerant and glucoseintolerant women: impact on cardiovascular mortality. Diabetes Care 2003;26:2883-9.

14. Tamasi JA, Vasilov A, Shimizu E, Benton N, Johnson J, Bitel $\mathrm{CL}$, et al. Monocyte chemoattractant protein- 1 is a mediator of the anabolic action of parathyroid hormone on bone. J Bone Miner Res 2013;28:1975-86.

15. Sukumar D, Partridge NC, Wang X, Shapses SA. The high serum monocyte chemoattractant protein-1 in obesity is influenced by high parathyroid hormone and not adiposity. J Clin Endocrinol Metab 2011;96:1852-8.

16. Park KS, Ahn KJ, Kim BJ, Kim HJ, Yoo SM, Kim JY, et al. Circulating concentrations of monocyte chemoattractant protein-1 are associated with menopause status in Korean women. Clin Chim Acta 2009;403:92-6. 